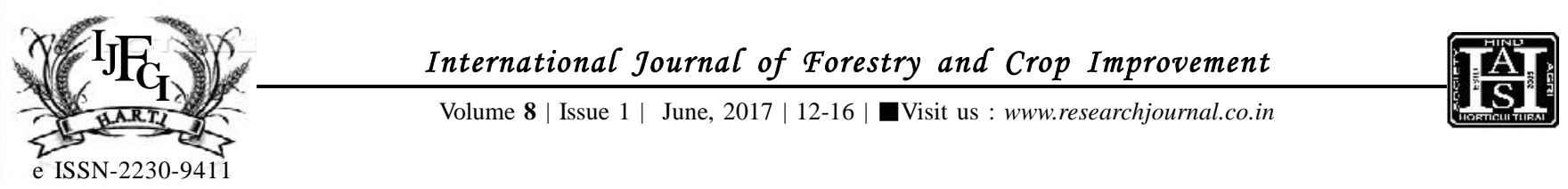

\title{
Estimation of variability and genetic parameters for nut characters (weight, diameter and length) in the seedling raised natural walnut (Juglans regia L.) population in the Kashmir valley
}

\author{
IMTIYAZAHMADLONE
}

\begin{abstract}
The present investigation entitled estimation of variability and genetic parameters for nut characters (weight, diameter and length) in the seedling raised natural walnut (Juglans regia L.) population in the Kashmir valley was carried out in order to document the available genetic variability in walnut germplasm and to select elite walnut genotypes possessing superior attributes and quality traits. During the survey, data was recorded on one hundred fifty two (152) walnut trees growing in different areas of Kashmir valley. Remarkable variability was observed in seedling walnut trees for different morphological, nut and kernel characters. Similarly, variations were also reported for other characters viz., tree vigour, growth habit, branching habit, leaflet shape, shoot colour, nut shape, shell texture, shell colour, shell seal, shell strength, shell integrity, kernel shrivel and kernel colour. studied the nut length varied from 30.0-60.0 mm with a population mean of $55.62 \pm 3.28 \mathrm{~mm}$. The phenotypic and genotypic variance was 605.14 and 427.56, corresponding to their co-efficients of variation to the extent of 44.25 and 37.17 per cent, respectively. Heritability (broad sense) and expected gain (\% of the mean) was 70.65 per cent and 64.36, respectively. Nut weight revealed a population mean of $14.48 \pm 2.54 \mathrm{~g}$ with a range of 8.50-30.0 $\mathrm{g}$. The phenotypic (18.785) and genotypic (12.760) variance when translated into their respective co-efficients of variation gave the estimate of 27.98 and 23.02 per cent, respectively. Broad sense heritability was 67.9 per cent and expected genetic gain (\% of the mean) as 39.15.
\end{abstract}

KEY WORDS : Walnut, Nut characterises, Weight, Lenth

HOW TO CITE THIS ARTICLE : Lone, Imtiyaz Ahmad (2017). Estimation of variability and genetic parameters for nut characters (weight, diameter and length) in the seedling raised natural walnut (Juglans regia L.) population in the Kashmir valley. Internat. J. Forestry \& Crop Improv., 8 (1) : 12-16, DOI: 10.15740/HAS/IJFCI/8.1/12-16.

Article Chronical : Received : 10.04.2017; Revised : 26.04.2017; Accepted : 06.05.2017 